Corrigendum

\title{
Corrigendum to "Toxic Effects of Trazodone on Male Reproductive System via Disrupting Hypothalamic-Pituitary- Testicular Axis and Inducing Testicular Oxidative Stress"
}

\author{
Sinem Ilgın (D), ${ }^{1}$ Gözde Aydoğan-Kılıç, ${ }^{2}$ Merve Baysal, ${ }^{1}$ Volkan Kılıç, ${ }^{2}$ Mina Ardıç, \\ Şeyda Uçarcan, ${ }^{2}$ and Özlem Atlı (iD) \\ ${ }^{1}$ Faculty of Pharmacy, Department of Pharmaceutical Toxicology, Anadolu University, Eskisehir, Turkey \\ ${ }^{2}$ Faculty of Science, Department of Biology, Anadolu University, Eskisehir, Turkey \\ Correspondence should be addressed to Sinem Ilgın; silgin@anadolu.edu.tr
}

Received 19 September 2018; Accepted 24 September 2018; Published 5 November 2018

Copyright (c) 2018 Sinem Ilgin et al. This is an open access article distributed under the Creative Commons Attribution License, which permits unrestricted use, distribution, and reproduction in any medium, provided the original work is properly cited.

In the article titled "Toxic Effects of Trazodone on Male Reproductive System via Disrupting HypothalamicPituitary-Testicular Axis and Inducing Testicular Oxidative Stress" [1], there was a missing grant number. An acknowledgment should be added as follows:

"This study was supported by Anadolu University Scientific Research Projects Commission, (Grant Number: 1401S018)".

\section{References}

[1] S. Ilgın, G. Aydoğan-Kılıç, M. Baysal et al., "Toxic effects of trazodone on male reproductive system via disrupting hypothalamic-pituitary-testicular axis and inducing testicular oxidative stress," Oxidative Medicine and Cellular Longevity, vol. 2018, Article ID 7196142, 12 pages, 2018. 


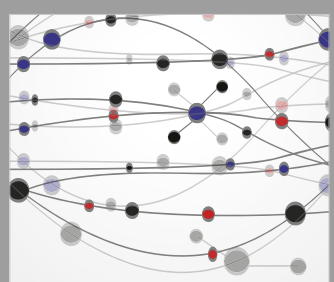

The Scientific World Journal
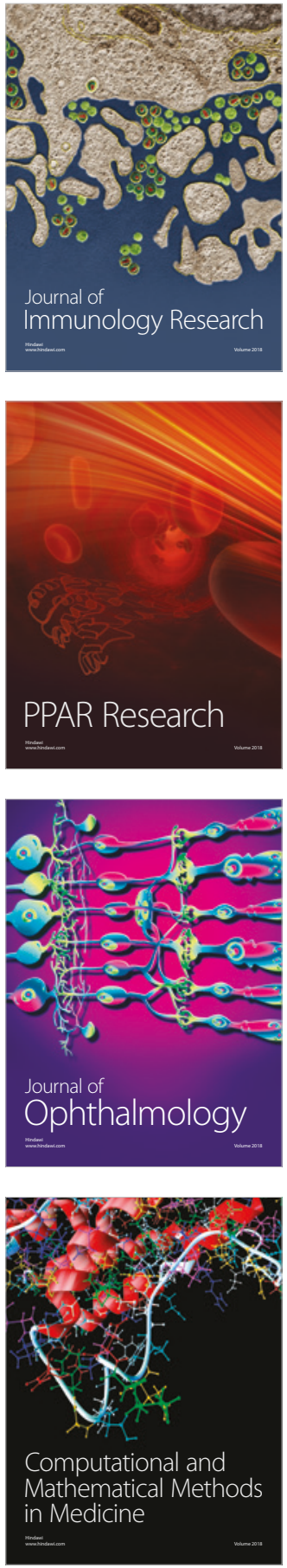

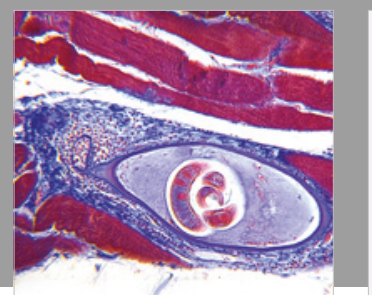

Gastroenterology Research and Practice

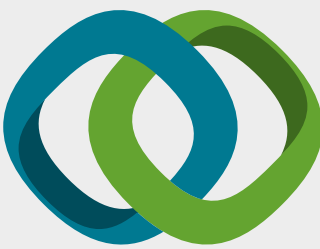

\section{Hindawi}

Submit your manuscripts at

www.hindawi.com
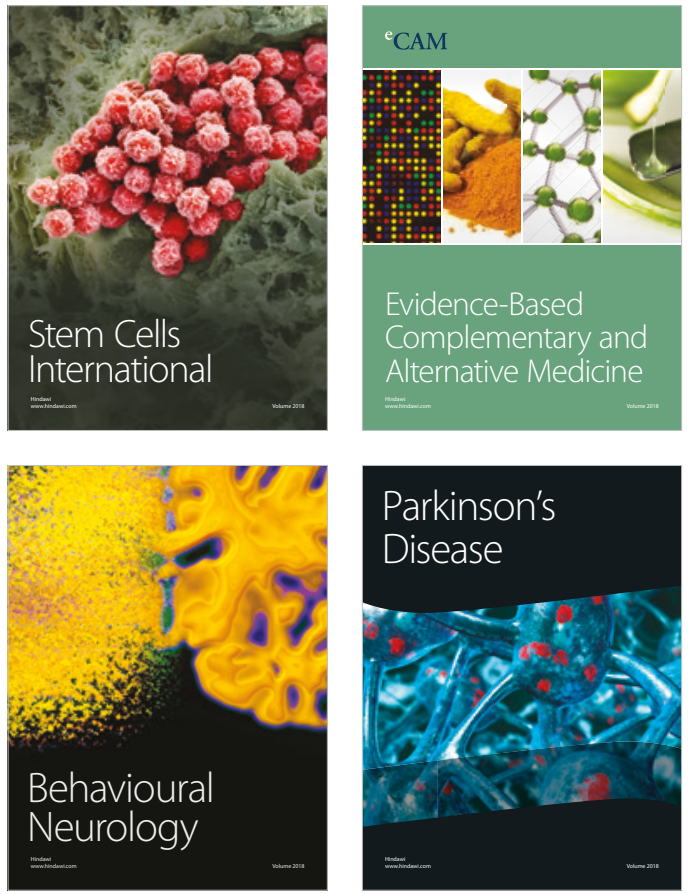

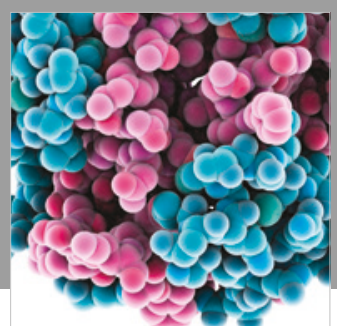

ournal of

Diabetes Research

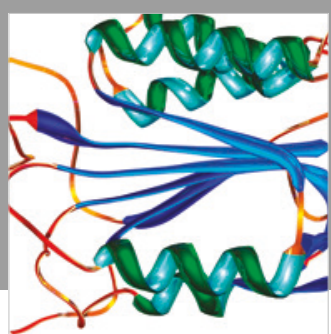

Disease Markers
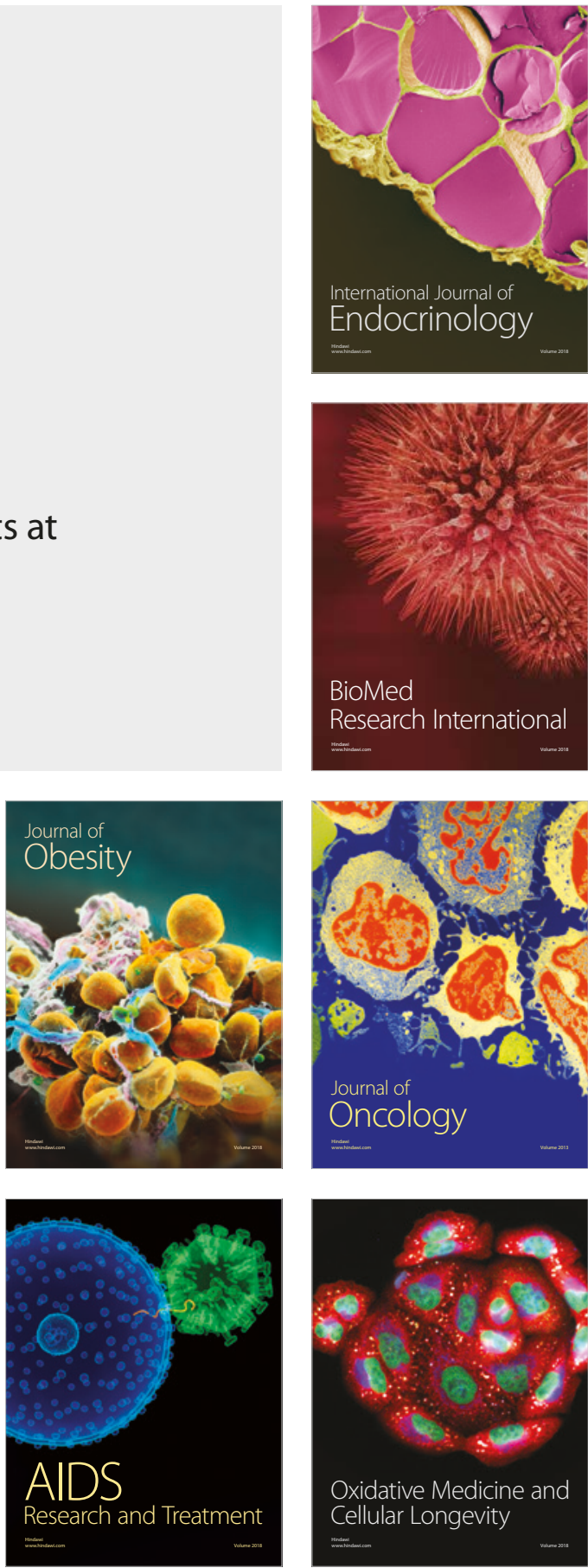